\title{
Formation of di-oxygen species on Ag anion clusters
}

\author{
Young Dok Kim *, Gerd Ganteför \\ Department of Physics, University of Konstanz, Universitätsstrasse 10, D-78457 Konstanz, Germany
}

\begin{abstract}
Experiments using vibrationally resolved ultraviolet photoelectron spectroscopy show that oxygen selectively adsorbs on evennumbered Ag anion clusters, whereas the odd-numbered clusters are not chemically active. We provide evidence that $\mathrm{O}_{2}$ molecularly adsorbs on $\mathrm{Ag}$ anion clusters consisting of less than 15 atoms. $\mathrm{O}_{2}$ adsorption pattern for $\mathrm{Ag}$ anion clusters is quite analogous to that of $\mathrm{Au}$ anion clusters. We suggest that for the reactions efficiently catalyzed by Au-nanocatalysts, Ag nanoclusters can be a promising candidate as a building block of catalysts.
\end{abstract}

Since gold $(\mathrm{Au})$, known as an inert material as bulk form, was found to become active with a cluster size below 3-4 nm, extensive studies have been performed to obtain a better understanding on catalytic process on Au clusters [1-9]. In surface chemistry, previous studies on Au-based catalysts have been often performed using model catalysts consisting of metal particles on wellordered oxide surfaces with relatively broad particle size distributions [1-3]. Recently, mass-selected clusters were deposited onto the oxide surfaces to create monodispersed metal clusters, which is required to better understand the cluster size dependent changes of cata-

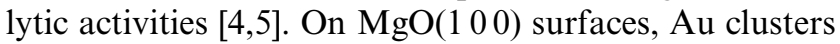
consisting of between 8 and 20 atoms turned out to efficiently catalyze CO-oxidation, whereas smaller $\mathrm{Au}$ clusters are catalytically inert [4]. In combination with density functional theory (DFT) calculations, it was suggested that Au clusters interacting with F-centres of $\mathrm{MgO}(100)$ are responsible for the high catalytic activities towards $\mathrm{CO}$-oxidation as a consequence of the charge transfer from $\mathrm{F}$ centres to Au clusters [4]. These results are in line with previous studies for $\mathrm{Au}$-islands grown on $\mathrm{TiO}_{2}(110)$, which suggested that the oxygen vacancies of $\mathrm{TiO}_{2}$ can lead to the charge transfer to yield negatively charged $\mathrm{Au}$ particles [6].

* Corresponding author. Fax: +49-7531-88-3888.

E-mail address: young.kim@uni-konstanz.de (Y. Dok Kim).
Recently, gas-phase Au anion clusters appeared to be suitable model system to shed light on reaction mechanisms of Au-nanocatalysis [7-9]. The Au anion clusters in the gas phase were shown to be chemically as active as deposited Au particles [8]. Studies on anionic clusters of $\mathrm{Au}$ are also relevant for Au-based catalysts consisting of $\mathrm{Au}$ particles and oxide supports, taking into account that the active gold particles in heterogeneous catalysis are negatively charged [17-19]. Studies for the $\mathrm{O}_{2}$ adsorption on free Au anion clusters identified molecularly bound oxygen at room temperature, which was suggested to be important intermediate species in many reactions efficiently catalyzed by $\mathrm{Au}$ nanoclusters [9]. It is remarkable that the important reaction intermediate such as di-oxygen species, which was so far difficult to identify using surface analysis tools, can be detected employing experimental techniques of cluster physics. This result implies that combinations of surface chemistry and cluster physics are promising strategy to unveil reaction mechanisms of the reactions catalyzed by nanoparticles. It is also important to mention that comparison of gas phase data and results from deposited clusters can shed light on the metal-support interaction, which is one of the most important subjects in heterogeneous catalysis.

The increased catalytic activities of particles with confined sizes seem to be not limited to Au, but also relevant for other materials. For example, Ag nanoparticles 
were found to show similar catalytic activities to those of Au clusters for the partial oxidation of hydrocarbons and low temperature $\mathrm{CO}$-oxidation, implying that high catalytic activities of small nanoparticles can be also relevant for other coinage metal clusters such as Ag and $\mathrm{Cu}$ [10]. Therefore, studies on chemisorption of $\mathrm{Ag}$ and $\mathrm{Cu}$ gas phase clusters can provide important information to better understand catalytic process of $\mathrm{Ag}$ - and $\mathrm{Cu}-$ based nanocatalysis.

In the present work, studies for $\mathrm{O}_{2}$ adsorption on $\mathrm{Ag}$ anion clusters in the gas phase are carried out. Similar to the $\mathrm{Au}$ anion clusters, even/odd alterations were observed for the $\mathrm{O}_{2}$ adsorption on $\mathrm{Ag}$ anion clusters, i.e. even numbered $\mathrm{Ag}$ anion clusters are generally active towards $\mathrm{O}_{2}$ adsorption, whereas the odd-numbered cluster are not [7-9,11]. Ultraviolet photoelectron spectroscopy (UPS) spectra on $\mathrm{Ag}_{n} \mathrm{O}_{2}^{-}$( $n=$ number of $\mathrm{Ag}$ atoms) clusters show that oxygen is non-dissociatively bound on $\mathrm{Ag}$ anion clusters. These results are quite analogous to those from $\mathrm{Au}$ anion clusters [9], suggesting that $\mathrm{Ag}$ nanoclusters can be as active as Au nanocatalysts for those reactions, for which stabilization of activated di-oxygen species is important.

To synthesize $\mathrm{Ag}_{n} \mathrm{O}_{2}^{-}$( $n=$ number of gold atoms), $\mathrm{Ag}$ clusters were produced in the pulsed arc cluster ion source (PACIS), and subsequently exposed to $\mathrm{O}_{2}^{-}$ $[12,13]$. The temperature of the clusters is estimated to be room temperature. The mass of clusters was selected using a time-of-flight (TOF) mass spectrometer, and the UPS spectra of the mass-selected clusters were taken using UV laser pulse (photon energy $=4.66 \mathrm{eV}$ ).

In Fig. 1, TOF mass spectra collected for the $\mathrm{Ag}$ anion clusters after reaction in $\mathrm{O}_{2}$ environments are displayed. Upon reacting with $\mathrm{O}_{2}$, the peaks corresponding to the $\mathrm{Ag}_{n}^{-}$with $n=$ even numbers become smaller, whereas the peak intensity of the respective $\mathrm{Ag}_{n} \mathrm{O}_{2}^{-}$clusters increases. In Fig. 1, it is evident that $\mathrm{Ag}_{16}^{-}$and $\mathrm{Ag}_{18}^{-}$are less active than other even-numbered $\mathrm{Ag}$ anion clusters. The peaks of the odd-numbered $\mathrm{Ag}$ anion clusters do not change upon exposing to $\mathrm{O}_{2}$, indicating that these clusters are inert towards $\mathrm{O}_{2}$ adsorption under these experimental conditions. The even/ odd alteration in $\mathrm{O}_{2}$ chemisorption reactivity has been already found for $\mathrm{Au}$ and $\mathrm{Ag}$ anion clusters in previous studies $[7-9,11]$. It is interesting to note that the even/ odd alteration in the oxygen adsorption reactivities can be still observed for the clusters consisting of more than 30 atoms in Fig. 1 (except $\mathrm{Ag}_{32}^{-}$), which is quite different from the result of $\mathrm{Au}$ anion clusters. Note that the $\mathrm{Au}$ anion clusters larger than $\mathrm{Au}_{20}^{-}$are inert towards $\mathrm{O}_{2}$ adsorption [9].

The even/odd-alteration for the $\mathrm{O}_{2}$ adsorption on the $\mathrm{Au}$ anion clusters has been explained within an electronic model [7-9]. The even-numbered $\mathrm{Au}$ anion clusters show lower electron affinities with respect to the odd-numbered neighbours [14]. The Au anion clusters
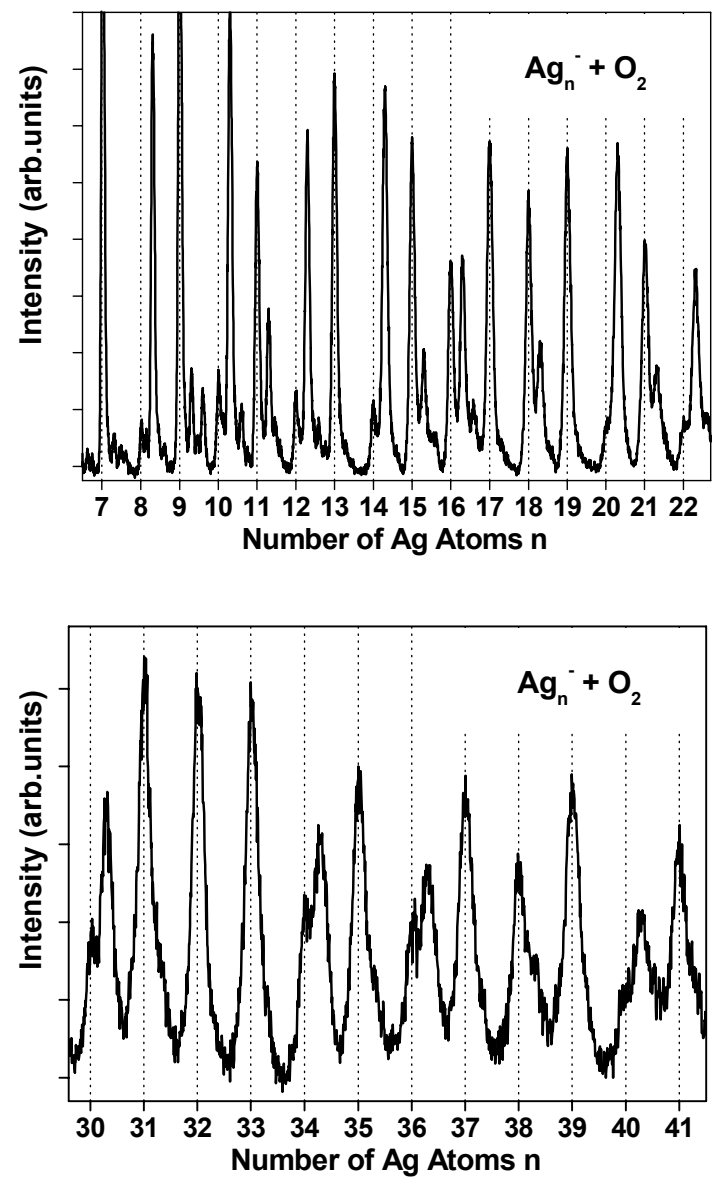

Fig. 1. Mass spectra of the $\mathrm{Ag}$ anion clusters after reaction with $\mathrm{O}_{2}^{-}$. The grids correspond to the masses of the bare Ag anion clusters. The top trace displays the Ag anion clusters with lower masses, whereas the bottom one corresponds to the larger clusters. Note that only evennumbered $\mathrm{Ag}$ anion clusters react with $\mathrm{O}_{2}^{-}$

with lower electron affinities can facilitate the electron transfer to $\mathrm{O}_{2}$, resulting in higher reactivities towards $\mathrm{O}_{2}$ adsorption. In contrast, the clusters with higher electron affinities cannot lead to the charger transfer to the adsorbates, decreasing the $\mathrm{O}_{2}$ adsorption activities. $\mathrm{Au}$ anion clusters larger than $\mathrm{Au}_{20}^{-}$are inert towards $\mathrm{O}_{2}$ adsorption, which can be also explained by higher electron affinities of these larger clusters.

It seems to be reasonable that the $\mathrm{Ag}$ anion clusters show even/odd-behaviours for the $\mathrm{O}_{2}$ adsorption (Fig. 1), analogous to the case of $\mathrm{Au}$, since the zig-zag pattern of the electron affinities as a function of cluster size can be also found for $\mathrm{Ag}$ [14]. Our observation that $\mathrm{Ag}_{16}^{-}$and $\mathrm{Ag}_{18}^{-}$are less reactive than other evennumbered neighbours also reconciles the relatively high electron affinities of these clusters. However, it is important to note that the absolute electron affinities of $\mathrm{Ag}$ anion clusters are generally significantly lower that those of $\mathrm{Au}$ anion clusters with similar sizes [14]. The electron affinities of the even-numbered $\mathrm{Au}$ anion clusters consisting of less than 20 atoms, which are active towards 
$\mathrm{O}_{2}$ adsorption, are lower than $3.4 \mathrm{eV}$, whereas the inactive $\mathrm{Au}$ anion clusters have electron affinities above $3.4 \mathrm{eV}$ [14]. The electron affinities of $\mathrm{Ag}_{n}^{-}$with $n=$ even and odd numbers are at highest $3.2 \mathrm{eV}$ [14]. Assuming that the absolute electron affinity is the criterion for the reactivity towards $\mathrm{O}_{2}$ adsorption, then not only evennumbered but also odd-numbered $\mathrm{Ag}$ anion clusters should be reactive towards $\mathrm{O}_{2}$ adsorption. Our experimental observation for the even/odd behaviours of the $\mathrm{Ag}$ clusters towards $\mathrm{O}_{2}$ adsorption suggests that the absolute electron affinities cannot be a sufficient criterion to determine the reactivity towards $\mathrm{O}_{2}$ adsorption.

In spite of much higher electron affinities of Au anion clusters with respect to the respective Ag anion clusters, $\mathrm{Au}$ and $\mathrm{Ag}$ anion clusters consisting of less than 21 atoms show similar activity pattern towards the $\mathrm{O}_{2}$ adsorption. This result can be interpreted in terms of strong $\mathrm{d}$ characters in the valence band of the Au clusters. Previous quantum calculations have found very strong d-sp mixing for Au, and the UPS spectra of the pure $\mathrm{Au}$ anion clusters also agree with these calculations [14-18]. In contrast to $\mathrm{Au}, \mathrm{Ag}$ valence band exhibits more or less pure sp-characters. It is possible that $\mathrm{d}$ orbitals play an important role for the chemisorption of $\mathrm{O}_{2}$, since the d-orbitals can overlap better with $\mathrm{O}_{2} 2 \pi^{*}$ orbitals with respect to the sp-states due to the symmetry reason. Because of the larger d-characters in the valence electronic levels of $\mathrm{Au}$ anion clusters, evennumbered $\mathrm{Au}$ anion clusters can be as reactive as $\mathrm{Ag}$ anion clusters for $\mathrm{O}_{2}$ adsorption, in spite of relatively high electron affinities of even-numbered $\mathrm{Au}$ anion clusters with respect to those of the respective $\mathrm{Ag}$ anion clusters.

To shed light on structural properties of $\mathrm{Ag}_{n} \mathrm{O}_{2}^{-}$, UPS experiments were carried out (Fig. 2). Electron affinities of the most of the Ag anion clusters displayed in Fig. 2 are shifted to higher binding energies by $0.5-0.9 \mathrm{eV}$ upon $\mathrm{O}_{2}$ adsorption [14]. For $\mathrm{Ag}_{2}^{-}$and $\mathrm{Ag}_{8}^{-}$, the $\mathrm{O}_{2}$ adsorption results in increase of the electron affinities by $1.3 \mathrm{eV}$, which is larger than in the case of other Ag anion clusters [14,19]. Oxygen acts as an electron-withdrawer, and the increase of the electron affinities by $\mathrm{O}_{2}$ adsorption is comparable to those of $\mathrm{Au}$ anion clusters $(0.6-1.1 \mathrm{eV})$ [20]. Note that dissociative adsorption of $\mathrm{O}_{2}$ should result in a larger increase of the electron affinities with respect to the molecular adsorption, since in a simple model, $\mathrm{O}_{2}$ is one-electron-acceptor, whereas two oxygen atoms formed by dissociative adsorption of $\mathrm{O}_{2}$ withdraw four-electrons from metals. Similar changes in electron affinities for $\mathrm{Ag}$ and $\mathrm{Au}$ anion clusters upon $\mathrm{O}_{2}$ adsorption suggest that the adsorption structures of $\mathrm{O}_{2}$ on $\mathrm{Au}$ and $\mathrm{Ag}$ anion clusters can be similar, i.e. $\mathrm{O}_{2}$ molecularly adsorb on these $\mathrm{Ag}$ anion clusters $[9,20]$.

Only for $\mathrm{Ag}_{2} \mathrm{O}_{2}^{-}$and $\mathrm{Ag}_{8} \mathrm{O}_{2}^{-}$, periodic structures are observed in the UPS spectra corresponding to about

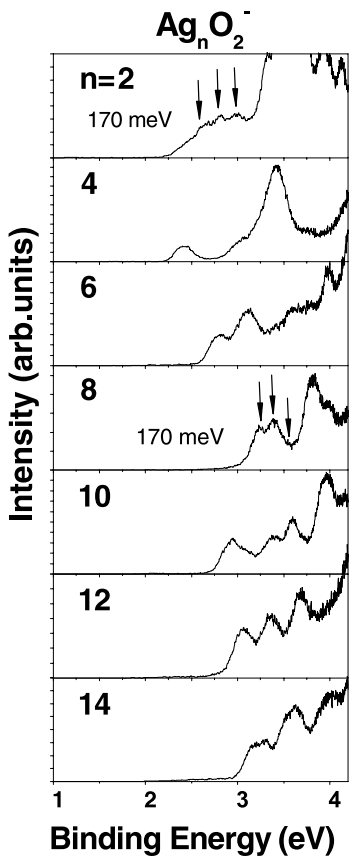

Fig. 2. UPS spectra of the $\mathrm{Ag}$ anion clusters reacted with $\mathrm{O}_{2}^{-}$(photon energy $=4.66 \mathrm{eV}$ ). Vibrational fine structures are denoted with arrows.

$170 \mathrm{meV}$, which can be assigned to the stretching frequency of $\mathrm{O}-\mathrm{O}$ (Fig. 2) [9]. Note that the periodic structures of the UPS of anions correspond to the vibration quantum of the neutral states with identical geometries to those of the anionic counterparts (Franck-Condon profile). Observation of the $\mathrm{O}-\mathrm{O}$ stretching frequency at the lower binding energy regimes in the UPS spectra of $\mathrm{Ag}_{2} \mathrm{O}_{2}^{-}$and $\mathrm{Ag}_{8} \mathrm{O}_{2}^{-}$indicates that the detachments of the electrons with the lowest binding energies in $\mathrm{Ag}_{2} \mathrm{O}_{2}^{-}$and $\mathrm{Ag}_{8} \mathrm{O}_{2}^{-}$change the $\mathrm{O}-\mathrm{O}$ distance significantly. This implies that the excess electron in the anionic state should be localized in $\mathrm{O}_{2}$, i.e., superoxospecies $\left(\mathrm{O}_{2}^{-}\right)$are formed in this case. For other clusters without the vibrational fine structures in the UPS spectra, the excess electrons in the anionic states are rather delocalized in the clusters. As mentioned above, the electron affinities of $\mathrm{Ag}_{2}^{-}$and $\mathrm{Ag}_{8}^{-}$increase upon $\mathrm{O}_{2}$ adsorption by about $1.3 \mathrm{eV}$, which is significantly larger than the values for other $\mathrm{Ag}$ anion clusters in Fig. 2. This result also reconciles larger $\mathrm{Ag} \rightarrow \mathrm{O}_{2}$ charge transfers for $\mathrm{Ag}_{2}^{-}$and $\mathrm{Ag}_{8}^{-}$with respect to the other $\mathrm{Ag}$ anion clusters in Fig. 2. The larger charge transfer for $\mathrm{Ag}_{2}^{-}$and $\mathrm{Ag}_{8}^{-}$to $\mathrm{O}_{2}$ can be rationalized within the electronic shell model. By removing one electron from the $\mathrm{Ag}_{2}^{-}$and $\mathrm{Ag}_{8}^{-}$, the closed shell structures $\left(1 \mathrm{~s}^{2}\right.$, or $1 \mathrm{~s}^{2} 1 \mathrm{p}^{6}$ ) can be formed [20]. It is worth mentioning that we cannot rule out the possibility that oxygen partially dissociates on $\mathrm{Ag}$ anion clusters forming less abundant isomers, which are not much pronounced in the UPS spectra. In the present work, we focus on those isomers governing the low binding energy part of the UPS 
spectra, and the existence of different isomers is a subject of a forthcoming Letter.

We provide spectroscopic evidence that $\mathrm{O}_{2}$ is molecularly bound on $\mathrm{Ag}_{2}^{-}$and $\mathrm{Ag}_{8}^{-}$clusters. Other $\mathrm{Ag}$ anion clusters in Fig. 2 show less $\mathrm{Ag} \rightarrow \mathrm{O}_{2}$ charge transfers with respect to the case of $\mathrm{Ag}_{2}^{-}$and $\mathrm{Ag}_{8}^{-}$, which is evident from the electron affinity changes and the absence of vibrational fine structures corresponding to the $\mathrm{O}-\mathrm{O}$ stretching mode. Considering that dissociative adsorption requires much larger charge transfer from metal to $\mathrm{O}_{2}-2 \pi^{*}$ orbital, oxygen should be also molecularly bound on other Ag anion clusters in Fig. 2.

It is interesting to note that striking similarities between the UPS spectra of $\mathrm{Ag}_{n} \mathrm{O}_{2}^{-}$with those of $\mathrm{Au}_{n} \mathrm{O}_{2}^{-}$ can be eventually found (Fig. 3). For $\mathrm{Ag}_{2} \mathrm{O}_{2}^{-}$and $\mathrm{Au}_{2} \mathrm{O}_{2}$, broad features can be found at lower binding energies followed by several narrower peaks. For $\mathrm{Au}_{12} \mathrm{O}_{2}^{-}$and $\mathrm{Au}_{12} \mathrm{O}_{2}^{-}$, three distinct peaks are observed at the lower binding energy regimes. The valence band structure of these clusters are most likely dominated by the antibonding orbitals of oxygen $\left(\mathrm{O}_{2}-2 \pi^{*}\right)$, suggesting that the adsorption structures of $\mathrm{O}_{2}$ on these $\mathrm{Au}$ and $\mathrm{Ag}$ anion clusters are very analogous. These results again suggest that oxygen should be molecularly bound on these $\mathrm{Ag}$ anion clusters, like on $\mathrm{Au}$ anion clusters.

Larger Ag and Au clusters behave chemically completely differently, i.e. $\mathrm{Au}$ anion clusters larger than $\mathrm{Au}_{20}^{-}$ are inert towards $\mathrm{O}_{2}$ adsorption, whereas the Ag clusters consisting of more than $20 \mathrm{Ag}$ atoms are still reactive. However, the $\mathrm{O}_{2}$ adsorption patterns on $\mathrm{Ag}$ anion clusters in Fig. 2 are quite analogous to the case of the respective $\mathrm{Au}$ anion clusters. It should be emphasized that $\mathrm{Au}$ anion clusters smaller than $\mathrm{Au}_{20}^{-}$recently draw particular attention due to there extraordinarily high catalytic activities for those reactions, which involve

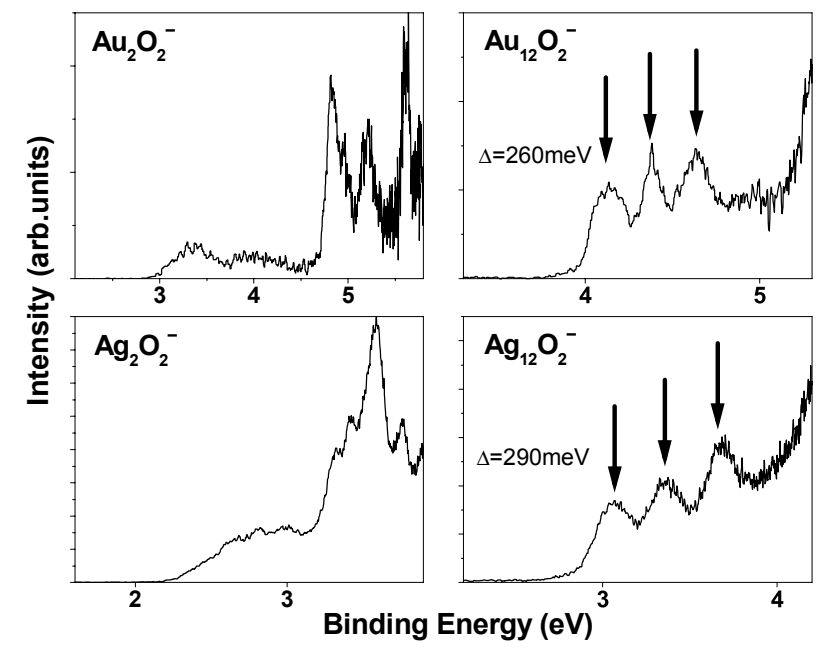

Fig. 3. UPS spectra of $\mathrm{Ag}_{n} \mathrm{O}_{2}^{-}$and $\mathrm{Au}_{n} \mathrm{O}_{2}^{-}$are compared for $n=2,12$. For $\mathrm{Ag}_{n} \mathrm{O}_{2}^{-}$the photon energy of $4.66 \mathrm{eV}$ was used for the UV-pulse, whereas for $\mathrm{Au}_{n} \mathrm{O}_{2}^{-} 6.4 \mathrm{eV}$ photon was used due to higher electron affinities of these clusters. oxygen adsorption. Based on our results, it is likely that that Ag-nanoclusters can be as active as Au-clusters for those reactions for which molecular oxygen is an important intermediate, for example CO-oxidation and partial oxidation of hydrocarbons [10].

We provide evidence that oxygen selectively adsorbs on even-numbered Ag anion clusters, whereas the oddnumbered clusters are not chemically active, which is quite analogous to $\mathrm{Au}$. Oxygen molecularly adsorbs on $\mathrm{Ag}$ anion clusters consisting of less than 15 atoms, forming superoxo-species, which is quite analogous to the results from the $\mathrm{Au}$ anion clusters with similar sizes. These results indicate that molecular adsorption of $\mathrm{O}_{2}$ at room temperature can be common phenomena for small coinage metal cluster anions. We suggest that for the catalytic reactions, for which molecular oxygen is an important reaction intermediate, not only $\mathrm{Au}$ but also Ag nanoclusters can be a possible candidate.

\section{Acknowledgements}

DFG (Deutsche Forschugnsgemeinschaft) is acknowledged for the financial support.

\section{References}

[1] M. Valden, X. Lai, D.W. Goodman, Science 281 (1998) 1647.

[2] T.S. Kim, J.D. Stiehl, C.T. Reeves, R.J. Meyer, C.B. Mullins, J. Am. Chem. Soc. 125 (2003) 2018.

[3] V.A. Bondzie, S.C. Parker, C.T. Campbell, J. Vac. Sci. Technol. A 17 (1999) 1717.

[4] A. Sanchez, S. Abbet, U. Heiz, W.-D. Schneider, H. Häkkinen, R.N. Barnett, U. Landman, J. Phys. Chem. A 103 (1999) 9573.

[5] H. Häkkinen, S. Abbet, A. Sanchez, U. Heiz, U. Landman, Ang. Chem. Int. Ed. 42 (2003) 1297.

[6] Z. Yang, R. Wu, D.W. Goodman, Phys. Rev. B 61 (2000) 14066.

[7] W.T. Wallace, R.W. Whetten, J. Am. Chem. Soc. 124 (2002) 7499.

[8] B.E. Salisbury, W.T. Wallace, R.L. Whetten, Chem. Phys. 262 (2000) 131

[9] D. Stolcic, M. Fischer, G. Ganteför, Y.D. Kim, Q. Sun, P. Jena, J. Am. Chem. Soc. 125 (2003) 2848.

[10] L.A. de Oliveira, A. Wolf, F. Schüth, Catal. Lett. 73 (2001) 157.

[11] T.H. Lee, K.M. Ervin, J. Phys. Chem. 98 (1994) 10023.

[12] C.-Y. Cha, G. Ganteför, W. Eberhardt, Rev. Sci. Instrm. 63 (1992) 5661 .

[13] S. Burkart, N. Blessing, B. Klipp, J. Müller, G. Ganteför, G. Seifert, Chem. Phys. Lett. 301 (1999) 546.

[14] K.J. Taylor, C.L. Pettiette-Hall, O. Cheshnovsky, R.E. Smalley, J. Chem. Phys. 96 (1992) 3319.

[15] S. Rabii, C.Y. Yang, Chem. Phys. Lett. 105 (1984) 480.

[16] A.F. Ramos, R. Arratia-Perez, G.L. Malli, Phys. Rev. B 35 (1987) 3790 .

[17] K. Balasubramanian, K.K. Das, Chem. Phys. Lett. 186 (1991) 577.

[18] C.W. Bauschlicher Jr., Chem. Phys. Lett. 156 (1989) 91.

[19] H. Handschuh, C.-Y. Cha, H. Möller, P.S. Bechthold, G. Ganteför, W. Eberhardt, Chem. Phys. Lett. 227 (1994) 496.

[20] W.A. Heer, Rev. Mod. Phys. 65 (1993) 611. 